\title{
A Cross-Layer Wireless Sensor Network Energy-Efficient Communication Protocol for Real-Time Monitoring of the Long-Distance Electric Transmission Lines
}

\author{
Jun Yu and Xueying Zhang \\ College of Information Engineering, Taiyuan University of Technology, Taiyuan, Shanxi 030024, China \\ Correspondence should be addressed to Xueying Zhang; tyzhangxy@163.com
}

Received 7 June 2014; Revised 6 October 2014; Accepted 16 November 2014

Academic Editor: Gongfa Li

Copyright (C) $2015 \mathrm{~J}$. Yu and X. Zhang. This is an open access article distributed under the Creative Commons Attribution License, which permits unrestricted use, distribution, and reproduction in any medium, provided the original work is properly cited.

\begin{abstract}
Optimization of energy consumption in Wireless Sensor Network (WSN) nodes has become a critical link that constrains the engineering application of the smart grid due to the fact that the smart grid is characterized by long-distance transmission in a special environment. The paper proposes a linear hierarchical network topological structure specific to WSN energy conservation in environmental monitoring of the long-distance electric transmission lines in the smart grid. Based on the topological structural characteristics and optimization of network layers, the paper also proposes a Topological Structure be Layered Configurations (TSLC) routing algorithm to improve the quality of WSN data transmission performance. Coprocessing of the network layer and the media access control (MAC) layer is achieved by using the cross-layer design method, accessing the status for the nodes in the network layer and obtaining the status of the network nodes of the MAC layer. It efficiently saves the energy of the whole network, improves the quality of the network service performance, and prolongs the life cycle of the network.
\end{abstract}

\section{Introduction}

Wireless Sensor Networks (WSN) have achieved various functions such as environmental collaborative awareness of a number of microsensor nodes in the deployed observation areas, distributed processing of data information, selforganization information communication network, and so forth, by combining the microsensor technique, data processing technique, and information network communication technique. Therefore, WSNs have been widely applied to various fields such as home automation, precision agriculture, safety monitoring, smart grids, and smart cities [14]. Energy supply for WSN nodes has become a bottleneck that influences its further wide applications in engineering practice due to local special conditions in its application environments (military areas, depopulated areas, deep-water areas, areas without communication signals, etc.). Effective reduction of energy consumption has become the research focus of current WSN technical engineering on the premise of ensuring reliable communication of WSN nodes.
The long-distance transmission electric line corridors in the smart power grids span various complex natural environments. Wide attention has been paid to such problems as damage to electrical insulators, detachment of spacer bars, and collapse of power transmission towers. The problem is due to various aspects, such as temperature and humidity, changes in wind power and wind speed, collision by flyers in the air, all of which accelerates the rusting and aging of lines $[5,6]$. Collecting and monitoring the environmental information of the long-distance transmission electrical lines by the WSN technique further promote the informatization and intellectualization levels of the smart power grids. Energy consumption management in the WSN node protocols becomes one of the critical links in engineering of realtime monitoring of smart power grids. The IEEE802.15.4 network protocol standard has been widely used for its simple structure, low cost, low energy consumption, and so forth. The ZigBee protocol defines the network layer, application layer, and the security mechanism based on the IEEE802.15.4 
standard (physical layer, MAC layer) and achieves engineering application of mobile nodes of the ZigBee network in such aspects as industrial control, security, protection monitoring, and environmental monitoring [7].

In terms of protocol layer, the methods for optimizing and improving the WSN communication protocols can be divided into two types, that is, hierarchical design and crosslayer design. The architecture of the network communication protocol based on the hierarchical design method reflects high applicability but a series of problems emerge in the wireless communication environment, such as access conflict, interuser interference, and signal fading. Intrinsic characteristics of the hierarchical design make it possible to share the information among various layers and fail to allow the protocol stack to maximize the use of the limited spectrum resources and power resources. Meanwhile, it lacks the capacity to adapt to environmental changes and needs to be improved in optimization of global network and adaption to independent network environment. Transfer sharing of specific information of various layers is achieved on the basis of the cross-layer design method. Meanwhile, a global adaptive adjustment is applied using the information exchange and application environment changes in order to form the global optimization design characterizing in overall constraining, information sharing, and independent adjustments [8].

The innovative points of this thesis are as follows.

(1) The paper proposes a WSN topological structure and a networking strategy applicable to the long-distance electric transmission lines in the smart grid.

(2) The paper involves design of a zonal topological structure routing protocol with hierarchical configuration available and an improved MAC layer protocol, which achieve the cross-layer optimization strategies for the MAC layer and the network layer. Based on the simulation testing, the communication protocol not only achieves network energy conservation but also exhibits perfect performance in throughput, end-toend delay, and so forth.

\section{Related Works}

Smart grids integrate the modern information technology to the traditional energy network enabling the power grid to significantly improve in such aspects as management controllability, data visualization, supervision reliability, safety of ration and maintenance, interaction friendliness, and environmental adaptation. For instance, distributed clean energy resources have been widely developed and used in such aspects as large-scale access, real-time scheduling, and storage depending on the smart grid technology $[9,10]$. The WSN technology provides an effective approach for overall awareness of the smart grid and reliable information resources for observability of power grids [11]. Therefore, the research and application of smart grids based on WSN have aroused wide attention $[12,13]$. As the power grids are intrinsically characterized by long-distance transmission in a special environment, energy consumption optimization for
WSN nodes has become the key link that constrains their engineering application, that is, WSN energy conservation strategies under the condition of limited energy $[14,15]$. In accordance with the WSN energy conservation strategies, they can be divided into single-layer network protocol optimization strategy and cross-layer network protocol optimization strategy.

In the single-layer network protocol optimization strategy, independent functional layers serve as the analysis or optimization objects, for instance, effect of the parameter setting and changes in data packet rate of the MAC layer on the network performance under the nonbeacon mode [16], energy management routing approach using Dijkstra's algorithm and software agents [17], and so forth.

With the increasing individual needs of WSN engineering applications, many problems arise, such as channel time varying, limited energy, redundant operations in cross-layer data transmission, isolation of single-layer information during network optimization, waste of frequency spectrum and power resources, and so on [18]. Besides, the single-layer network protocol optimization strategy is slightly inadequate in optimization of global network performance. The cross-layer network protocol optimization strategy provides an effective solving idea exactly for the above problems. The cross-layer network protocol optimization strategy is a comprehensive design method for various functional layers. It exerts the intrinsic characteristics of the network to the largest extent and gives consideration to the demand for network energy conservation [19-21], thus optimizing the network resources and maximizing the function application [13, 22-26].

\section{WSN Cross-Layer Network Protocol and Energy Optimization Strategy}

3.1. WSN Communication Protocol. The WSN protocol stack can be divided into six parts: Physical Layer, Data Link Layer, Network Layer, Transmission Control Layer, Application Support Layer, and Network Management Layer. The corresponding relationship in various layers between the IEEE 802.15.4 protocol standard and ZigBee protocol standard is shown in Figure 1 [26].

The scientific research personnel has designed many types of WSN communication protocols based on the above network structure system, for example, AODV routing protocol, IEEE 802.15.4 MAC protocol, and so forth.

3.1.1. IEEE 802.15.4 MAC Protocol. The IEEE 802.15.4 MAC protocol is a low power consumption optimized network communication protocol. The IEEE 802.15.4 network includes three devices, namely, terminal, coordinator, and PAN coordinator. The IEEE 802.15.4 MAC has two operating modes [27]: nonbeacon-enabled mode and beacon-enabled mode. In the nonbeacon-enabled mode network, the nodes access the channels using the unslotted Carrier Sense Multiple Access/with Collision Avoidance (CSMA/CA) mechanism. Under the beacon-enabled mode, communication between nodes within the network is arranged with the superframe as the cycle. One superframe is divided into 16 time 


\begin{tabular}{|c|c|c|c|}
\hline User & \multicolumn{2}{|c|}{ Application support layer } & Topology control \\
\hline \multirow{3}{*}{ ZigBee_- } & Transmission control layer & \multirow{5}{*}{$\begin{array}{c}\text { Network } \\
\text { management } \\
\text { layer }\end{array}$} & Energy management \\
\hline & Network laver & & QoS support \\
\hline & & & Network security \\
\hline \multirow{2}{*}{$\begin{array}{c}\text { IEEE } \\
802.15 .4 \\
\downarrow\end{array}$} & Data link layer & & Mobility control \\
\hline & Physical layer & & Remote management \\
\hline
\end{tabular}

FIGURE 1: The protocol stack of WSN.

slots. The beacon frame (BF) sent by the network coordinator is transmitted in the first time slot of the superframe and the remaining 15 time slots are used as Contention Access Period (CAP) and Contention Free Period (CFP) (Figure 2).

A superframe is defined by beacon interval (BI) and superframe duration (SD). BI defines the time interval between two consecutive beacon frames, namely, length of a superframe and transmission period of a beacon frame. SD defines the duration of the active time frame in a superframe. When $\mathrm{BI}>\mathrm{SD}$, there will be an inactive time frame in a superframe. A nonactive time frame means that the node may enter into a sleep mode for achieving the energy conservation. The duration of BI and SD depends on a constant defined in the specification: a base super frame duration (BSFD) and two parameters, that is, beacon order (BO) and superframe order (SO). Consider

$$
\begin{array}{r}
\mathrm{BI}=\mathrm{a} \text { Base Superframe Duration } \times 2^{\mathrm{BO}}, \\
0 \leq \mathrm{BO} \leq 14, \\
\mathrm{SD}=\text { a Base Superframe Duration } \times 2^{\mathrm{SO}}, \\
0 \leq \mathrm{SO} \leq \mathrm{BO} \leq 14 .
\end{array}
$$

According to the IEEE 802.15.4 MAC protocol, the value range of $\mathrm{BO}$ is from 0 to 14 ; when $\mathrm{BO}=15$, it indicates that the node device does not use the superframe structure; the value range of $\mathrm{SO}$ is also from 0 to 14 and it is guaranteed that $\mathrm{SO}$ is less than $\mathrm{BO}$; when $\mathrm{SO}=\mathrm{BO}$, it indicates that the superframe does not include nonactive period. The superframe and the size of its time slot can be defined by modifying the parameters mentioned above. These values can be adjusted in accordance with different applications to improve the network performance, namely, throughput capacity, and so forth [28].

3.1.2. AODV Routing Protocol. Ad hoc On-Demand Distance Vector (AODV) routing protocol [29] is a reactive routing protocol. The ZigBee network layer can achieve the selforganization and self-healing capability functions by using the AODV routing protocol.

In the network using the AODV routing protocol, it will first search the route of the target node in the existing routing table when the source node needs to establish a path to transmit data to the target node. The source node will transmit the data to the target node along the path if there is an available route; on the contrary, it will send a flooding broadcasting route request (RREQ) data packet from the source node to the neighbor node (Figure 3).

To control the broadcasting area of the RREQ data packet in the network, the source nodes use the expanding ring search technique to initialize the time to live (TTL) value of the route request. If no response is received in the cycle, a progressive increase will start in accordance with a predefined increment value until a route is found or the TTL value reaches the predefined threshold value. When an intermediate node retransmits the PREQ, it will first receive and record the address of the neighbor node of the broadcast packet thus establishing a reverse path. The node will transmit a corresponding route reply (RREP) to the source node in a unicast manner if there is a RREQ target node or an intermediate node with a new path leading to the target node. The intermediate node along the path will establish a forward direction path leading to the target node in its routing table when the RREP is transmitted back along the reverse path. When the RREP reaches the source node, the path is established (Figure 4). The path will be maintained until the source node has a new demand for path establishment. If the source node moves, route discovery is launched again to find a new path leading to the target mode; if the target mode or some intermediate node moves, the upstream nodes will delete the route entries and send route error (RERR) messages to the affected upstream neighbor nodes. RERR is back propagated to the source node. The source nodes affected can choose to stop sending data or send a new PREQ message to relaunch the process of route discovery.

WSN is a network technique of the engineering application type. Its hardware structure and communication protocol have certain adaptability but it is still required to analyze the target characteristics and strategies based on the individual needs in the application environment to achieve an overall plan for communication protocol based on the WSN topological structure. The original MAC protocol and AODV routing protocol (OM-AODV) communication protocol is formed by combining the above IEEE 802.15.4 MAC protocol and AODV routing protocol. The paper achieves the design and optimization of the routing protocol based on the OMAODV routing protocol.

\subsection{WSN Topological Structure and Network Establishment Strategies for Long-Distance Electric Transmission Lines}

3.2.1. Requirement Analysis. The structure of the environmental monitoring network of the long-distance high-voltage 


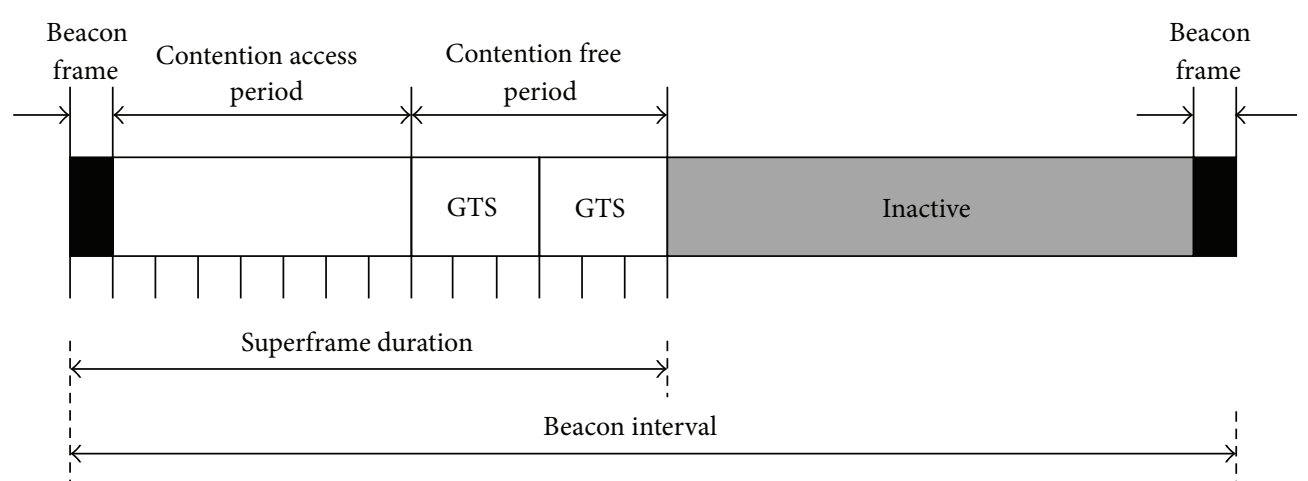

FIGURE 2: Structure of the superframe under the beacon-enabled mode.

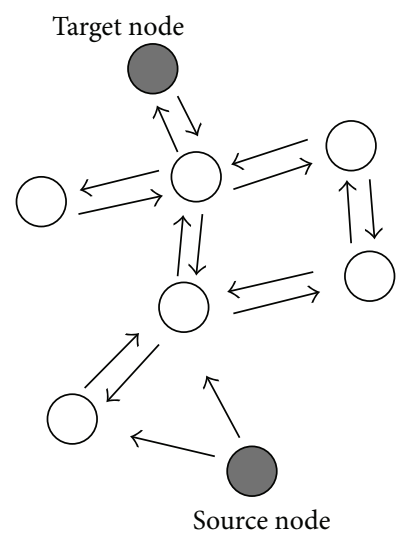

FIGURE 3: RREQ flooding broadcast.

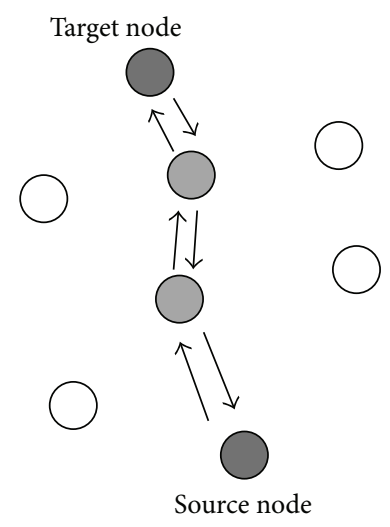

Figure 4: RREP unicast.

electric transmission lines in the smart grid exhibits dual characteristics, linear and reticular. Each electric transmission line starts from one transformer substation and terminates at another transformer substation. The line corridor is linear. Hence, from the viewpoint of an overall monitoring environment, the nodes comprise a long-distance linear communication network and the network topological structure is also linear. Arrangement of the network nodes of the whole line is repeated regularly due to the fact that the parameters of tower at each level to be monitored are basically consistent. Once the monitoring network of the electric transmission line is set up, the positions, functions of the nodes need not be changed; that is, the whole network structure is relatively fixed. Even if some nodes are moved as a result of galloping of electric transmission lines, the displacement distance can be ignored compared with the communication distance. Thus, it is generally acknowledged that no node movement exists in the whole network.

The nodes in the environmental monitoring network of the long-distance high-voltage electric transmission lines in the smart grid designed in the paper exhibit a high local density. A number of nodes are within the range of 50 meters from the tower. The whole linear network comprises a number of local areas. The local network topology is designed with the power as the unit in the whole network. Then the repeated local mesh networks comprise the linear network of the whole line.

\subsubsection{WSN Topological Structure and Network Establishment} Strategies. Design programming of the topological structure is the key link in the research on WSN engineering application. It sufficiently considers the topological structure in an actual application environment. The efficiency of data transmission between routing protocol and MAC protocol will be fully exerted. It can provide effective support for a series of network management functions such as data fusion, time synchronization, and node location. It can also reduce the energy consumption of the nodes to the greatest extent and prolong the life cycle of the whole network.

Generally, the WSN topological structure means that the unnecessary wireless communication links will be eliminated by power control and selection of backbone network nodes thus forming a network topological structure with highly efficient data transmission on the premise that the requirements of network coverage and connectivity indexes are met [30]. Engineering effect optimization can be achieved only by reasonable incorporation of the topological structure and the routing strategy. The paper proposes a topological structure model of the linear hierarchical network specific to energy constraints by transforming the WSN environmental monitoring for the long-distance electric transmission lines in the smart grid into an abstract topological structure. 
A zonal network topological structure is designed with hierarchical configuration available based on the distribution characteristics and demands of the nodes in the environmental monitoring network of the long-distance high-voltage electric transmission lines in the smart grid (Figure 5).

The zonal network topological structure with available hierarchical configuration divides the whole strip-shaped monitoring area into several subareas. In each subarea (i.e., cluster), the Internet network or General Packet Radio Service (GPRS)/Global System for Mobile Communications (GSM) public networks should be found nearby. Generally, a subarea is within the range of several kilometers or dozens of kilometers. WSN nodes are arranged in the subareas divided and the interval between each two clusters is approximately $600 \mathrm{~m}$ thus forming WSN clustering. The analytical methods within each cluster and group of clusters are basically the same. Thus, the cluster is used as the unit to analyze the network characteristics and optimize the protocols.

Each cluster comprises 24 sensor nodes of data collection, 4 intermediate-layer routing nodes, and 1 PAN coordinator node (cluster head). The intermediate routing nodes and sensor nodes are uniformly distributed around the PAN coordinator. The multihopping mode is used between member nodes and cluster head nodes and cluster head nodes themselves. Each node has the functions of sensing, shortdistance communication, and long-distance communications and yet these functions are not completely equivalent. The underlying sensor nodes activate the sensing and shortdistance communication function to acquire and retransmit data. The intermediate routing nodes activate the shortdistance communication function to retransmit data. The upper-layer cluster head nodes activate the short-distance and long-distance communication functions to collect data and upload them to the information center. Generally, the network topological structure does not cluster network unless the nodes fail and exit from the network. Thus, no complex route maintenance is required to 11 reduce the energy consumed in frequent path switching.

During the startup phase of the network operation, the cluster head establishes a mesh network and the member nodes will join the network as an intermediate-layer routing node or a sensor node. A transmission path will be established automatically between various member nodes and cluster head nodes by many-to-one route selection and source route selection. During the monitoring stage of the network operation, the monitoring center host will send query or control instructions to the data concentrator. The cluster head nodes will then retransmit the command frame to the member nodes by broadcast or unicast via the ZigBee PRO network. During the process of reverse data transmission, the routing nodes can directly send data to the cluster head by the unicast method for the network address of the cluster head is fixed. The cluster head nodes receive and summarize the data collected in the monitored areas to achieve quick and effective extended relay transmission of the packets monitored. Finally, the cluster head nodes will access the public networks (Internet, GPRS/GSM, etc.) to achieve the connection between WSN and external networks and then transmit the monitoring data back to the monitoring center.
TABLE 1: The frame format of the RREQ message.

\begin{tabular}{lcccc}
\hline $\begin{array}{l}\text { Type of broadcast } \\
\text { packet }\end{array}$ & $\begin{array}{c}\text { Flag } \\
\text { bit }\end{array}$ & $\begin{array}{c}\text { Hop } \\
\text { count }\end{array}$ & $\begin{array}{c}\text { Source } \\
\text { address }\end{array}$ & Node level \\
\hline RREQ & 1 & hop & src & level \\
\hline
\end{tabular}

In conclusion, the zonal network topological network with available hierarchical configuration and networking strategies have significant characteristics in high efficiency and energy conservation: (1) the zonal network topological structure with available hierarchical configuration can reduce the number of channel access times of the nodes by data aggregating thus improving the network performance; (2) real-time data transmission can be guaranteed by cluster head data transmission thus enabling most of the nodes in the network to consume low energy.

3.3. Zonal Topological Structure Routing Protocol with Hierarchical Configuration Available. The paper proposes a zonal topological structure with hierarchical configuration of node functions for the environmental monitoring network of the electric transmission lines specific to the characteristics of the long-distance high-voltage electric transmission lines in the smart grid and designs a routing protocol with Topological Structure be Layered Configurations (TSLC) based on the above. The TSLC routing protocol is a layered routing protocol, which adds its own route maintenance function after establishing an algorithm on the reverse path of the AODV routing protocol.

The TSLC routing protocol compromises PAN coordinator nodes, intermediate routing nodes, and sensor nodes. The PAN coordinator nodes send path request data packets and other nodes retransmit RREQ. A routing tree is formed with the PAN node as the center by flooding broadcast. Thus, the nodes in the network establish a reverse path to transmit and maintain data. Cross-layer collaboration can be performed based on the node identity during data maintenance. RERR packets can be sent when nodes fails. The relay nodes will respond to the RERR packets and send RREP packets thus recovering the interrupted links. Each node only maintains the route from the node to other nodes except the PAN nodes and there is no need to master the topological structure of the whole network.

3.3.1. Network Establishment Process of TSLC Routing Protocol. During the process of network establishment, the identities of various nodes and the hop count among the routing nodes, sensor nodes, and PAN coordinator nodes are determined first. Then, a route request packet RREQ is created by the PAN coordinator node and broadcasted to its neighbor nodes. The RREQ message is transmitted unidirectionally among network nodes. Independent lists of neighbor nodes are formed in network nodes based on the RREQ message (Figure 6). The frame format of the RREQ message is shown in Table 1.

During retransmission of the RREQ packets, the fields such as hop count, source address, node level will be updated. 

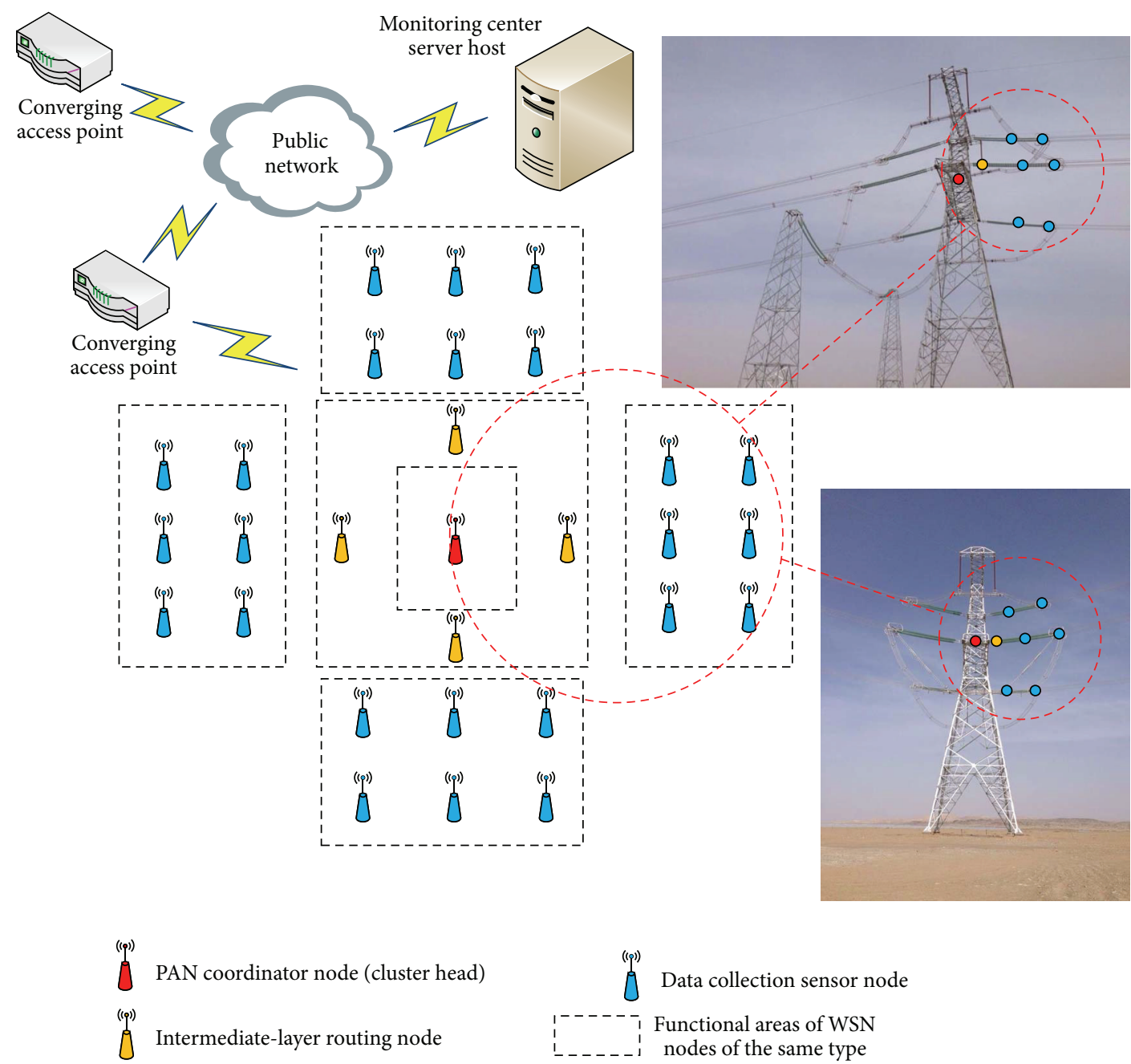

FIGURE 5: The zonal network topological structure with available hierarchical configuration.

The source address is the identity (ID) number of the retransmission node. During the initial stage of PAN flooding, the value of various node levels is set to 0 ; the level value will be plus 1 when the node receives a RREQ packet for the first time; the level value will be plus 1 again when the node receives a RREQ packet for the second time; the rest can be done in the same manner to form hierarchical distribution of nodes. When the path request is retransmitted, the hop count of the RREQ packet nodes transmitted will be updated and the hop count is the hop count of RREQ first received plus 1.

The routing node will respond to the PAN node after receiving RREQ. The address of the PAN coordinator node will be recorded as the target node of the previous hop during data transmission. Each node that receives the RREQ will update the source address in the RREQ message to its own ID address and retransmit the RREQ once. Its neighbor node (including PAN nodes and sensor nodes) will first judge whether itself is a PAN node based on ID after receiving RREQ. It will be judged as a PAN node if the ID is 0.Then, the node will add the source address in RREQ as a new one in the neighbor list and wait for transmission of data packets instead of retransmitting RREQ. Otherwise it will be judged as a sensor node and further judgment will be made to determine whether the node receives RREQ for the first time. If the node receives RREQ for the first time, the source address in RREQ will be added to its own neighbor list and the address will be used as the node of the previous hop during transmission of data packets thus establishing a reverse path. Then the source address in the RREQ message will be updated to its own ID address and retransmit the RREQ once. If it is not the first time for the node to receive RREQ it will neither respond nor retransmit RREQ thereby completing addition in the neighbor list. Establishment of the network and routing tree is completed and ready for transmission of data packets after the neighbor lists of all nodes are added (Algorithms 1).

To avoid any loop formed by the flooding RREQ, a network node will use the source node retransmitted by the path received for the first time as its own previous hop and only retransmit once. It will add neighbors and no longer retransmit RREQ under other conditions. The hop count will increase progressively if the network node receives RREQ for the first time. The hop count will be retransmitted to other 

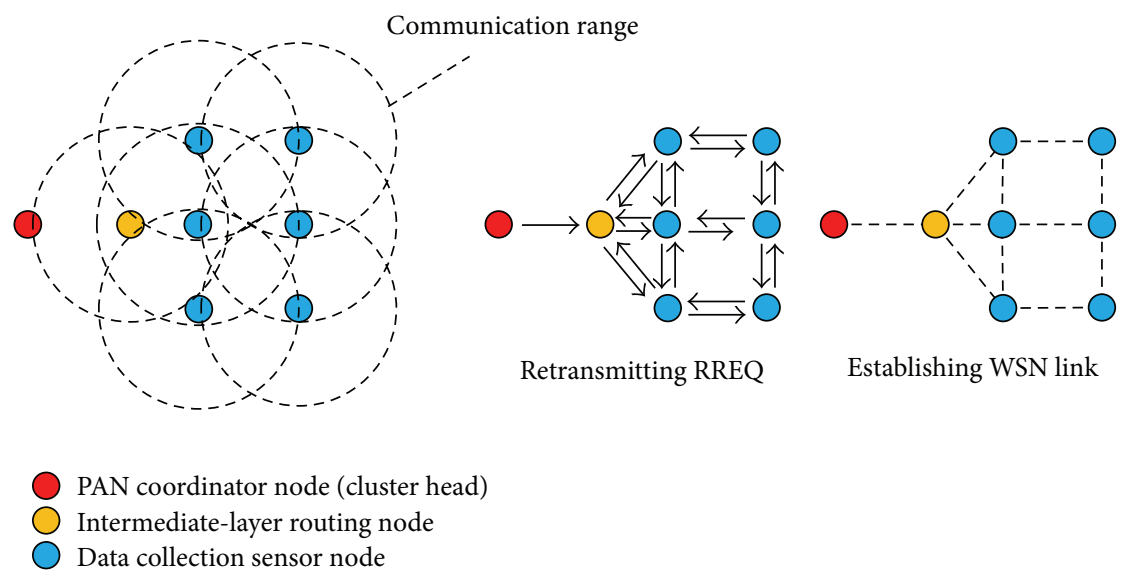

Figure 6: Process of TSLC route setup.

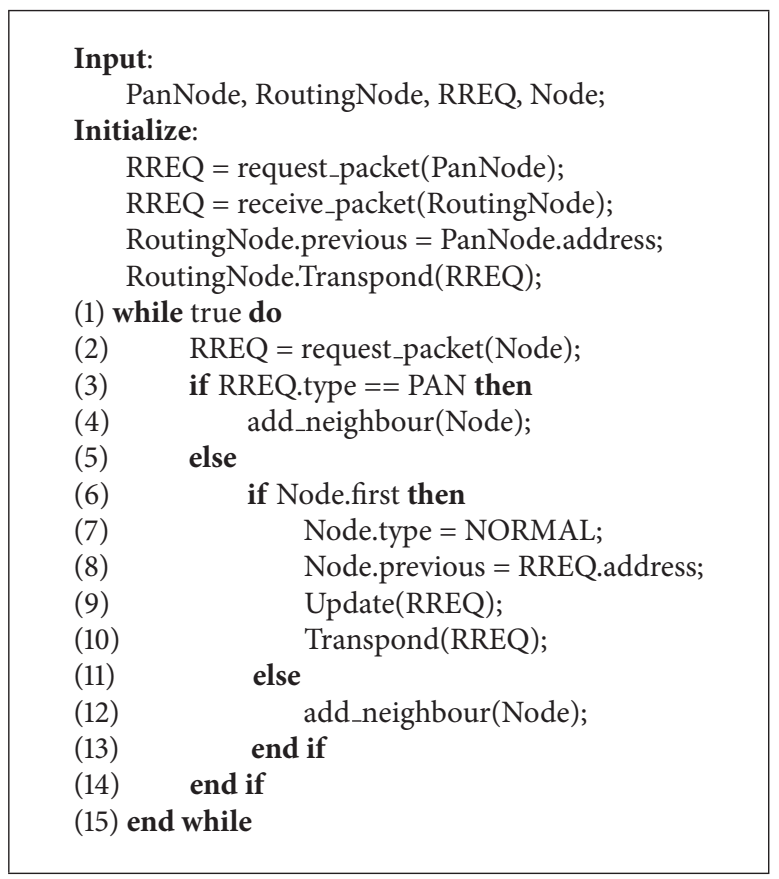

Algorithm 1: Break-routing establishment.

nodes during retransmission. The hop count of the repeatedly retransmitted RREQ will be plus 1 when the nodes in the network receive the retransmitted RREQ. The distance to the PAN coordinator nodes will be judged from the hop count.

3.3.2. Data Transmission Process of Sensor Nodes. Any sensor node can send data packets to the PAN coordinator nodes after network establishment thus enabling users to observe the environment remotely (Algorithm 2). Transmission of data packets includes two cases: (1) the nodes themselves are the sources of data transmitted and the data are transmitted by a routing tree; (2) the nodes only serve as relay nodes or coordinator nodes; the data packets will be received if they are coordinator nodes; the previous hop formed during broadcasting will be served as their destination address for retransmission of data packets if they are relay nodes.

3.3.3. Path Maintenance Strategies. A routing tree is formed with the coordinator as the center for transmission of data packets after TSLC network establishment. A node will transmit route error packets RERR if it is not able to reach the previous hop during transmission of data packets (Figure 7). The node will carry its own ID, hop count, and address of the failed nodes (its own previous hop) and cache the data packets when transmitting RERR packets. The frame format of the RERR message is as shown in Table 2, where the hop count is the one of the nodes that transmits RERR and signifies the distance to the coordinator node. The source address represents the ID number of the source node 


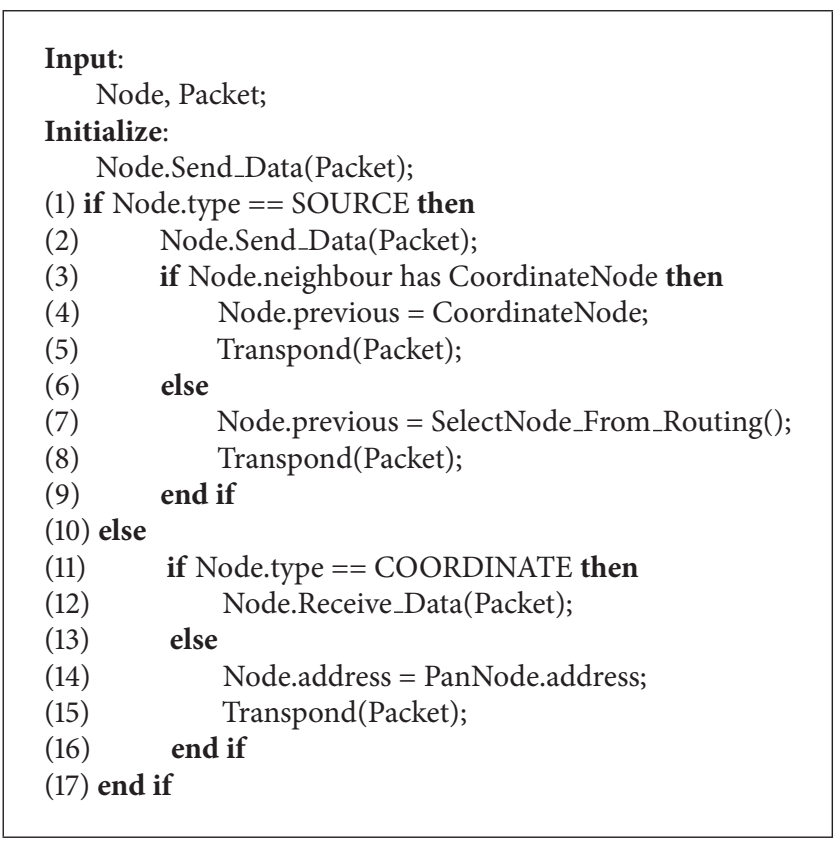

Algorithm 2: Data transmission process of sensor nodes.

TABLE 2: The frame format of the RERR message.

\begin{tabular}{lcccc}
\hline $\begin{array}{l}\text { Type of broadcast } \\
\text { packet }\end{array}$ & $\begin{array}{c}\text { Flag } \\
\text { bit }\end{array}$ & $\begin{array}{c}\text { Hop } \\
\text { count }\end{array}$ & $\begin{array}{c}\text { Source } \\
\text { address }\end{array}$ & $\begin{array}{c}\text { Destination } \\
\text { address }\end{array}$ \\
\hline RERR & 2 & hop & src & dest \\
\hline
\end{tabular}

TABLE 3: The frame format of the RREP message.

\begin{tabular}{lcccc}
\hline $\begin{array}{l}\text { Type of broadcast } \\
\text { packet }\end{array}$ & $\begin{array}{c}\text { Flag } \\
\text { bit }\end{array}$ & $\begin{array}{c}\text { Hop } \\
\text { count }\end{array}$ & $\begin{array}{c}\text { Source } \\
\text { address }\end{array}$ & $\begin{array}{c}\text { Destination } \\
\text { address }\end{array}$ \\
\hline RREP & 3 & hop & src & dest \\
\hline
\end{tabular}

that transmits RERR packets and the destination address represents the previous hop of the node.

When other nodes in the network receive RERR packets, it is required to judge (1) whether its own top count is less than that of the node that transmits RERR packets; (2) whether its previous hop node has the same address with the failed node. The node will compete for transmitting response frame RRER packets, delete the failed nodes, and update the neighbor list if its own hop count is less than that of the node transmitting RERR packets and its own previous hop is not a failed node. The source node that transmits RERR packets will select the one that first corresponds to RRER as its own previous hop. Thus, the link can be recovered from interruption and the cached data packets can be transmitted to a new previous hop. The frame format of the RREP message is shown in Table 3. The source node that transmits RREP packets and the address of its own previous hop are primarily carried when RREP is transmitted. The destination address of RREP packets is the source node that transmits RERR.
The original MAC protocol and TSLC routing protocol (OM-AODV) communication protocol is formed by combining the IEEE 802.15.4 MAC protocol and above TSLC routing protocol.

3.4. Cross-Layer Optimization of MAC Protocol. The IEEE 802.15.4 MAC protocol uses a fixed duty ratio and its sleep mechanism is not able to properly adapt to the varying network data transmission quantity. In the paper, the superframe duty ratio is adjusted through different status of the nodes so as to achieve dynamic adaptation of the data transmission quantity, that is, modified IEEE802.15.4 MAC protocol.

The length of the superframe cycles of all nodes specified in the simulation test model is constant and identical. The length of the superframe cycles is constant. The length of the activity cycle within a superframe can be determined by setting the activity index $\mathrm{SO}$. The quantity of the data sent by the computer and the length of superframe activity cycle are compared and matched to achieve reasonable distribution of the data transmission channels.

For nodes with large quantity of data transmission (inner layer of the network, i.e., PAN coordinator node and intermediate-layer routing nodes), the value of $\mathrm{SO}$ in the superframe can be increased to prolong its length of activation period. On one hand, the nodes should complete data transmission within the superframe as much as possible to reduce the probability of collision and shorten the time delay of collision; on the other hand, reducing the sleep time can promote completion of the data transmission task as a result of a high node load. The sleeping mechanism can even be canceled temporarily to ensure smooth operation of the data traffic under the condition of a high operational load. 


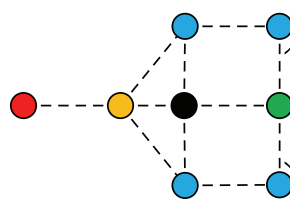

Transmitting RERR

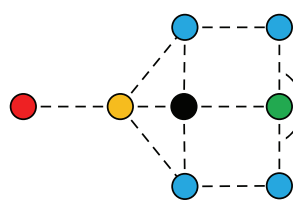

Transmitting RREP

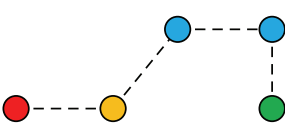

Recovering from interrupted links
PAN coordinator node (cluster head)

Intermediate-layer routing node

Data collection sensor node
Source node

Fault node

FigURE 7: Reconstruction after TSLC route interruption.

The probability of sleeping time occurrence can be effectively reduced by increasing the activity cycle.

For nodes with large quantity of data transmission (external layer of the network, i.e., data collection sensor nodes and intermediate-layer routing nodes), the SO value within the superframe should be decreased to shorten the time of the activation period thus enabling the nodes to generally enter a sleep mode under the condition of small quantity of data transmission. The transceiver can even be shut down for a long time to lower the energy consumption when the nodes do not transmit any data in a period of time.

The nodes in the network include PAN coordinator nodes, intermediate routing nodes, and sensor nodes. When transmitting data packets, the MAC layer obtains the status of a node by accessing the set cross-layer of the node in the network layer and dynamically adjusts the $\mathrm{SO}$ value in the protocol based on the node identity. The strategies for setting the $\mathrm{SO}$ value are as follows.

(1) For PAN coordinator nodes, the SO value remains unchanged.

(2) For intermediate-layer routing nodes, the activity cycle should be increased and the sleep time should be decreased due to a high load. Thus, the SO value should be increased (in the paper, for the router nodes in design, the SO value varies randomly from 6 to 9).

(3) For sensor nodes, the SO value should be decreased enabling the nodes to be in a sleep state for a long time under the condition of small quantity of data transmission so as to lower energy consumption (in the paper, the SO value of the sensor node varies randomly from 3 to 6 during design).

Coprocessing of the network layer and the MAC layer can save energy, reduce time delay, and improve the service quality. The modified MAC protocol and TSLC routing protocol (M2-TSLC) communication protocol is formed by combining the above modified MAC protocol and the TSLC routing protocol.

3.5. Testing and Analysis of Communication Protocol. A combinatorial analysis and comparison are conducted for the above three communication protocols, that is, original MAC protocol and AODV routing protocol (OM-AODV), original MAC protocol and TSLC routing protocol (OM-TSLC), and

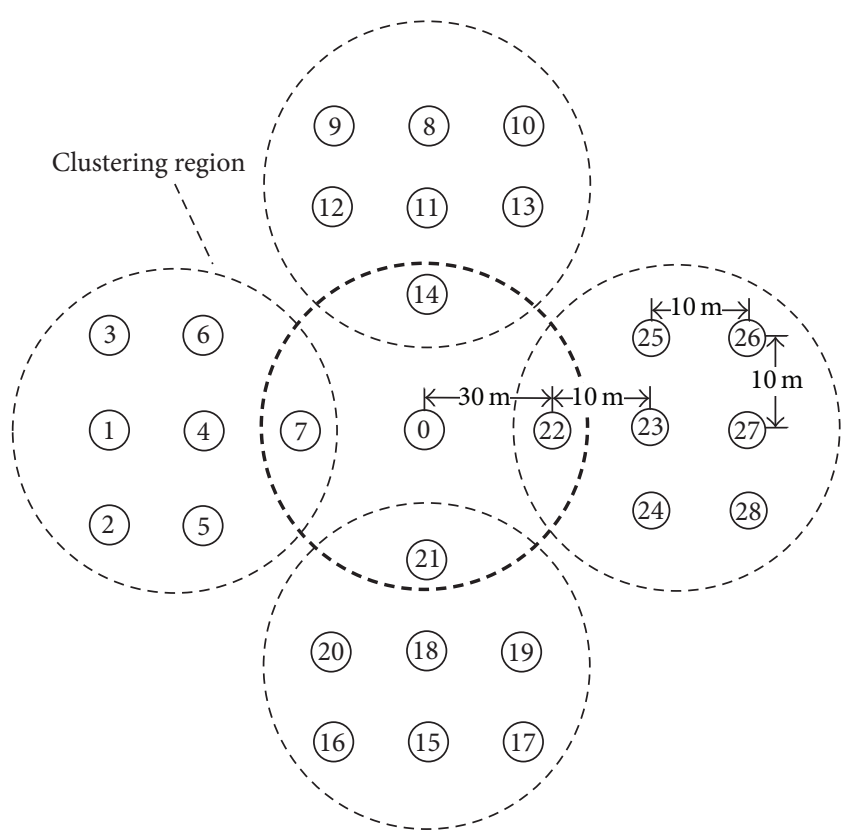

FIGURE 8: WSN layered symmetric topological structure.

modified MAC protocol and TSLC routing protocol (M2TSLC) by network emulator NS2. The WSN is of layered symmetric topological structure (Figure 8), where all sensor nodes have the same physical structure and the same data transmission radius. All communications among nodes use a two-way link. Each node at least has one neighbor node within its communication range. All nodes cannot move. The address of each node is distinguished by a different ID. Node 0 is the PAN coordinator node; nodes 7, 14, 21, and 22 are intermediate routing nodes; the hop count of the nodes reaching the PAN coordinator is 1 . The remaining ones are sensor nodes. The hop count between the sensor nodes and corresponding routing nodes is 1 or 2 . For example, the hop count between sensor nodes 4,5 , and 6 and their corresponding cluster head node (intermediate routing node) 7 is 1; the hop count between the sensor nodes 1,2, and 3 and their corresponding cluster head node (intermediate routing node) 7 is 2 . See Table 4 for the configuration parameters of the WSN network. 
TABLE 4: The configuration parameters of the WSN.

\begin{tabular}{lc}
\hline Parameter & Value \\
\hline Primary energy of node & $100 \mathrm{~J}$ \\
Size of data packet & $50 \mathrm{byte}$ \\
Node transmitting power & $110 \mathrm{~mW}$ \\
Idle listening power & $5 \mathrm{uW}$ \\
Communication radius of node & $30 \mathrm{~m}$ \\
Transmission interval for data Packets & $4 \mathrm{~s}$ \\
Node receiving power & $80 \mathrm{~mW}$ \\
Sleep mode power & $1114 \mathrm{nW}$ \\
\hline
\end{tabular}

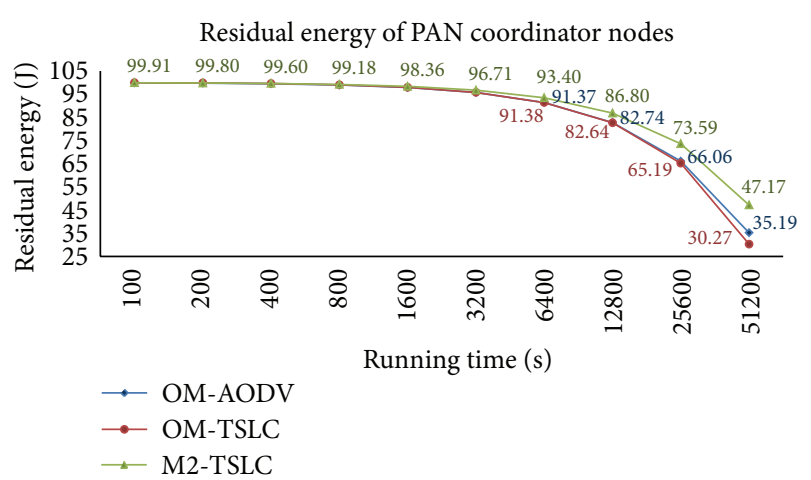

FIGURE 9: Residual energy of PAN coordinator nodes.

The communication protocol test uses the residual energy index and three-dimensional performance index [31], that is, throughput, end-to-end delay, packet delivery fraction to jointly evaluate the overall energy efficiency of the routing protocol.

3.5.1. Testing and Analysis of Energy-Efficiency. Based on the difference in function types of WSN nodes, the residual energy includes the residual energy of the PAN coordinator nodes, the average residual energy of the intermediate routing nodes, and the average residual energy of the sensor nodes. On the premise that the operation duration of the WSN nodes is $100 \mathrm{~s}, 200 \mathrm{~s}, 400 \mathrm{~s}, 800 \mathrm{~s}, 1600 \mathrm{~s}, 3200 \mathrm{~s}, 6400 \mathrm{~s}, 12800 \mathrm{~s}$, $25600 \mathrm{~s}$, and $51200 \mathrm{~s}$, the residual energy of WSN nodes of various types are tested as shown in Figures 9-11.

The PAN coordinator nodes are the functional nodes with the most frequent information exchange in WSN and their residual energy value will directly affect the overall operation duration of the whole network. The three communication protocols basically have the same residual energy when the PAN coordinator nodes and the intermediate routing nodes are running the time interval $[100 \mathrm{~s}, 3200 \mathrm{~s}]$; the M2-TSLC communication protocol exhibits significant advantages in energy conservation and the OM-AODV communication protocol is slightly superior to the OM-TSLC communication in energy conservation when running the time interval [6400 s, $51200 \mathrm{~s}$ ] (Figures 9 and 10).

The three communication protocols basically have the same residual energy when the residual energy of the sensor

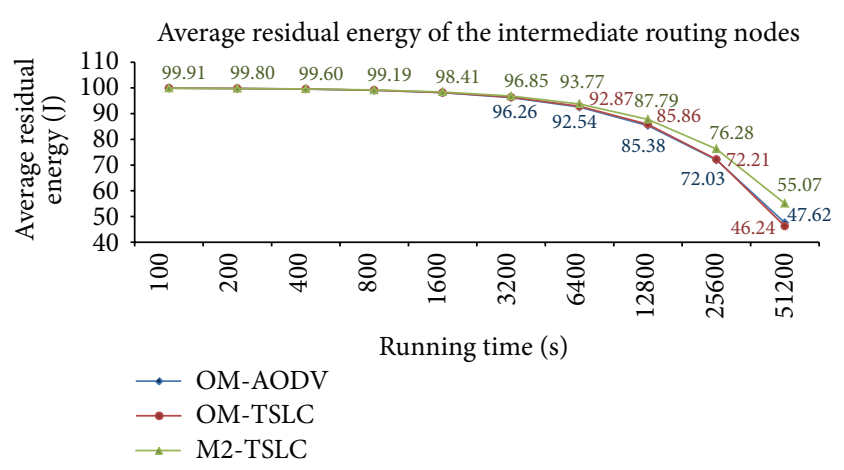

FIGURE 10: Average of residual energy of intermediate-layer routing nodes.

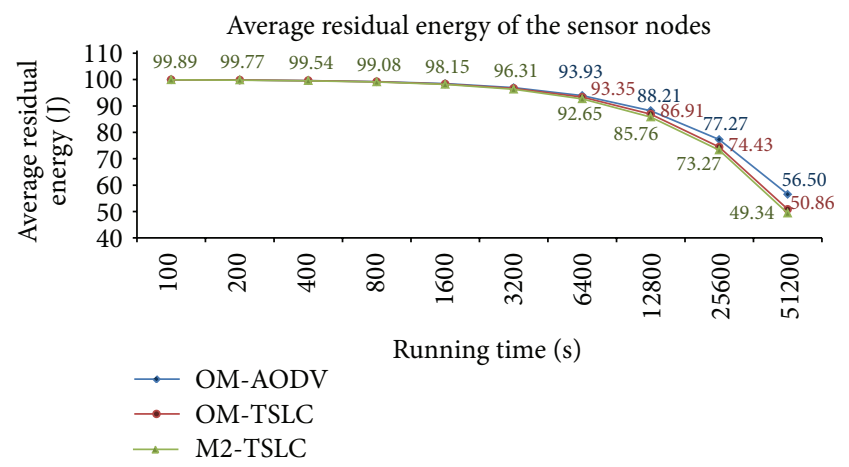

FIGURE 11: Energy average of sensor nodes.

nodes are running the time interval [100 s, $6400 \mathrm{~s}]$; the OMAODV communication protocol exhibits certain advantages when running the time interval [6400 s, $51200 \mathrm{~s}$ ] (Figure 11). However, the survival performance of the whole network depends on the residual energy of the critical functional nodes. The lifetime of the whole network can be prolonged if the residual energy of the PAN coordinator nodes and the intermediate-layer routing nodes is greater than the residual energy of the sensor nodes. Hence, the M2-TSLC communication protocol has obvious advantages in energy conservation from the viewpoint of the overall WSN residual energy.

3.5.2. Testing and Analysis of Network Performance. In the performance test, the three types of performance indexes of throughput capacity, end-to-end delay, and delivery rate are used to test the network performance. The three types of indexes present an objective evaluation of the network quality from different angles [32].

(1) Throughput Capacity. It is the number of the data packets that the WSN nodes receive and send within the unit time. It reflects the efficiency of the overall operation of WSN. Consider

$$
\text { Throughput capacity }=\frac{1}{n} \sum_{t=0}^{T_{n}}\left(N r_{t}+N s_{t}\right),
$$




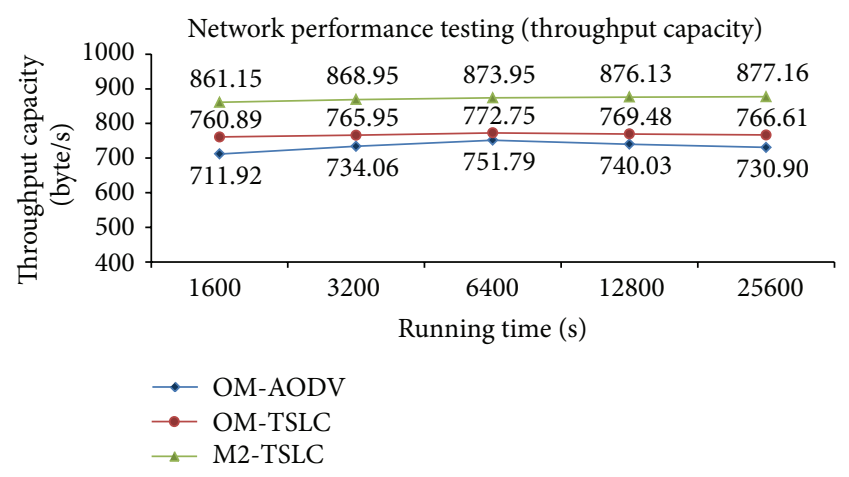

FIGURE 12: Test of WSN throughput capacity.

where $N r_{t}$ is the number of the data packets received by the goal nodes within $T$ time. $N s_{t}$ is the number of the data packets sent by the source nodes within $T$ time; $\sum_{t=0}^{T_{n}}\left(N r_{t}+\right.$ $\left.N s_{t}\right)$ is the sum of the data packets that the WSN data packets receive and send within $T_{n}$.

Based on the test of WSN throughput capacity, it is discovered that (Figure 12) the throughput capacity average of the M2-TSLC communication protocol is 871.47 byte/s. The throughput capacity averages of the OM-TSLC communication protocol and the OM-AODV communication protocol are 767.14 byte/s and 733.74 byte/s, respectively; that is, the throughput capacity performance of the M2-TSLC communication protocol is superior to the remaining two algorithms.

(2) End-to-End Delay. It is the average time consumed for the data packets transmitted from the source node to the goal node. The end-to-end delay includes interface queue cache, MAC layer retransmission, and sending and transmission time. Consider

$$
\text { End-to-end Delay }=\frac{1}{N} \sum_{i=0}^{N_{s}}\left(r t_{i}-s t_{i}\right)
$$

where $N_{s}$ is the total number of the data packets sent by the source node; $r t_{i}$ is the time when the goal node receives the $i$ th data packet; $s t_{i}$ is the time when the source node sends the $i$ th data packets; $\sum_{i=0}^{N_{s}}\left(r t_{i}-s t_{i}\right)$ is the total time delay of the WSN during sending and receiving of the data packets from the $i$ th data packet to the $N_{s}$ th data packet.

Based on the end-to-end delay test for WSN, it is discovered that (Figure 13) the end-to-end delay of the M2-TSLC communication protocol is lower than that of the remaining two algorithms. In addition, with continuous operation of the network, the advantages of the end-to-end delay of the M2-TSLC communication protocol are becoming significant gradually compared to the remaining two algorithms.

(3) Data Packet Delivery Rate. It describes the rate of successful transmission of the data packets from the source nodes to the goal nodes in WSN and reflects the data

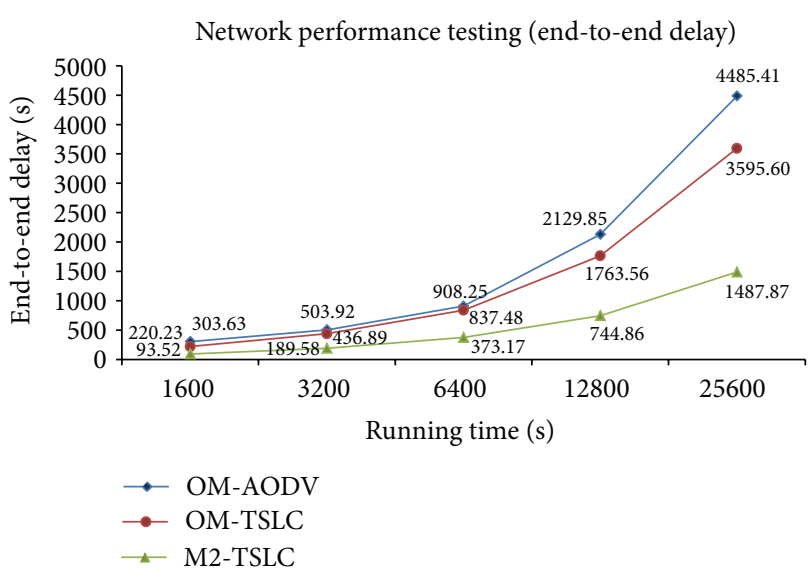

FIGURE 13: End-to-end delay test for WSN.

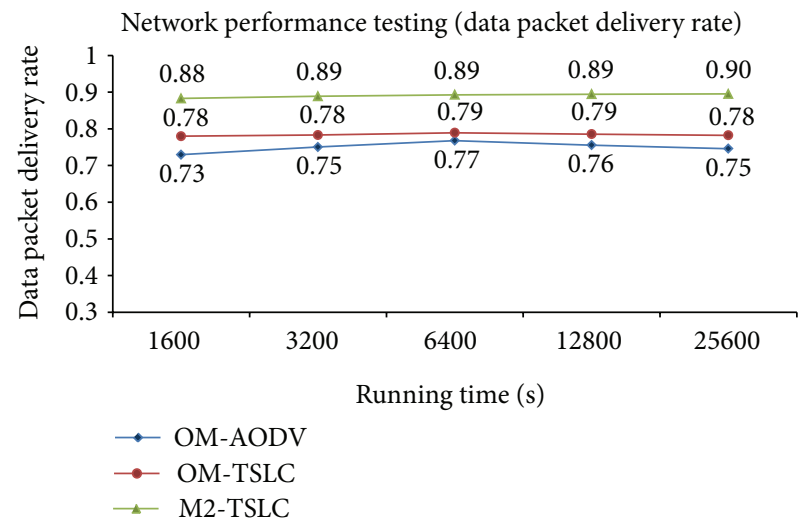

FIGURE 14: Test of WSN data packet delivery rate.

transmission efficiency and reliability of the routing protocol. The computing method is as follows:

$$
\text { Data Packet Delivery Rate }=\frac{N_{r}}{N_{s}},
$$

where $N_{r}$ is the number of data packets received by the goal node and $N_{s}$ is the number of the data packets sent by the source node.

Based on the test of WSN data packet delivery rate, it is discovered that (Figure 14) the delivery rate of the M2-TSLC communication protocol is 0.89 ; the throughput capacity averages of the OM-TSLC communication protocol and the OM-AODV communication protocol are 0.78 and 0.75 , respectively; that is, the delivery rate performance of the M2-TSLC communication protocol is superior to the remaining two algorithms.

In conclusion, the M2-TSLC communication protocol is superior to the remaining two communication protocols in energy conservation and three-dimensional performance indexes (throughput capacity, end-to-end delay, and data packet delivery rate). Therefore, the M2-TSLC communication protocol provides an energy-efficient network protocol 
strategy with superior performance for sensing and monitoring of the long-distance electric transmission lines in the smart grid.

\section{Conclusion}

The design achieves quick and effective extended relay transmission of the wireless monitoring data packets of the longdistance high-voltage electric transmission lines in the smart grid by using the energy consumption parameters of ZigBee hardware and protocol for WSN network establishment. Real-time monitoring is performed for the environmental parameters along the lines to achieve real-time warning and fault locating for electrical equipment as well as timely and effective maintenance measures thus ensuring normal electric transmission and minimizing any influence caused by the disasters. Based on the AODV routing protocol and IEEE 802.15.4 MAC protocol, the paper proposes a set of topological structures and network establishment strategies for long-distance electric transmission lines and optimizes the network using the cross-layer design method to achieve improvement of the network performance and reduction of energy consumption.

The paper evaluates the quality of the optimized network using the four types of indexes, namely, residual energy consumption, throughput capacity, end-to-end time delay, and delivery rate. As functional nodes with the most frequent information exchange in the network, the PAN coordinator nodes of the M2-TSLC communication protocol exhibit obvious advantages in energy conservation. In terms of the WSN global survival time, the M2-TSLC communication protocol has obvious advantages in energy conservation and the M2TSLC communication protocol is superior to the remaining two communication protocols in energy conservation, threedimensional performance indexes (throughput, end-to-end delay, and delivery rate of data packets). Therefore, the M2TSLC communication protocol provides an energy-efficient network protocol strategy with reliable communication performance for sensing and monitoring of the long-distance electric transmission lines in the smart grid.

\section{Conflict of Interests}

The authors declare that they have no competing interests.

\section{Acknowledgments}

This research work was supported by the National Natural Science Foundation of China (nos. 61072087 and 61371193), Scientific and Technological Research Projects (Social Development) of Shanxi Province China (no. 20120313013-6), Scientific Research Foundation for the Returned Overseas Chinese Scholars of Shanxi Province China (no. 2011-035), and Innovation Project of the Postgraduate Education in Shanxi Province 2011 (no. 20113029).

\section{References}

[1] A. Z. Abbasi, N. Islam, and Z. A. Shaikh, "A review of wireless sensors and networks' applications in agriculture," Computer Standards and Interfaces, vol. 36, no. 2, pp. 263-270, 2014.

[2] E. Popovici, M. Magno, and S. Marinkovic, "Power management techniques for wireless sensor networks: a review," in Proceedings of the 5th IEEE International Workshop on Advances in Sensors and Interfaces (IWASI '13), pp. 194-198, Bari, Italy, June 2013.

[3] M. S. Bensaleh, S. M. Qasim, A. M. Obeid, and A. GarciaOrtiz, "A review on wireless sensor network for water pipeline monitoring applications," in Proceedings of the International Conference on Collaboration Technologies and Systems (CTS '13), pp. 128-131, May 2013.

[4] V. Kaseva, T. D. Hämäläinen, and M. Hännikäinen, "A wireless sensor network for hospital security: from user requirements to pilot deployment," Eurasip Journal on Wireless Communications and Networking, vol. 2011, Article ID 920141, 2011.

[5] S. Gu, J. Chen, W. Chen, W. Feng, J. Guo, and Y. Zeng, "Method for lightning flashover warning of overhead transmission lines," High Voltage Engineering, vol. 39, no. 2, pp. 423-429, 2013.

[6] P. V. Hung, H. Yamaguchi, M. Isozaki, and J. H. Gull, "Large amplitude vibrations of long-span transmission lines with bundled conductors in gusty wind," Journal of Wind Engineering and Industrial Aerodynamics, vol. 126, pp. 48-59, 2014.

[7] F. Ouyang, Modeling and Optimization of Energy Consumption for ZigBee-Based Wireless Mobile Sensor Networks, Nanjing University, 2013.

[8] H. X. Zhang, D. F. Yuan, and Y. B. Ma, Eds., Cross-Layer Design for Wireless Commnications-From Principle to Application, Posts and Telecom Press, Beijing, China, 2010.

[9] A. Bari, J. Jiang, W. Saad, and A. Jaekel, "Challenges in the smart grid applications: an overview," International Journal of Distributed Sensor Networks, vol. 2014, Article ID 974682, 11 pages, 2014.

[10] J.-W. Cao, Y.-X. Wan, G.-Y. Tu et al., "Information system architecture for smart grids," Chinese Journal of Computers, vol. 36, no. 1, pp. 143-167, 2013.

[11] Z. Y. Liu, Ed., Smart Grid Technology, China Electric Power Press, Beijing, China, 2010.

[12] J. M. R. de Souza Neto, J. S. da Rocha Neto, L. Chang et al., "A self-calibrating partial discharge WSN for condition monitoring in the future smart grid," in Proceedings of the $3 \mathrm{rd}$ IEEE PES International Conference and Exhibition on Innovative Smart Grid Technologies (IEEE ISGT '13), pp. 1-7, 2013.

[13] I. Al-Anbagi, M. Erol-Kantarci, and H. T. Mouftah, "A delay mitigation scheme for WSN-based smart grid substation monitoring," in Proceedings of the 9th International Wireless Communications and Mobile Computing Conference (IWCMC '13), pp. 1470-1475, IEEE, Sardinia, Italy, July 2013.

[14] K.-H. Jung, H.-R. Lee, W.-S. Lim, and Y.-J. Suh, "An adaptive collision resolution scheme for energy efficient communication in IEEE 802.15.4 networks," Computer Networks, vol. 58, no. 1, pp. 39-57, 2014.

[15] M. Tahir, N. Javaid, A. Iqbal, Z. A. Khan, and N. Alrajeh, "On adaptive energy-efficient transmission in WSNs," International Journal of Distributed Sensor Networks, vol. 2013, Article ID 923714, 10 pages, 2013. 
[16] Z. Abbas, N. Javaid, M. A. Khan, S. Ahmed, U. Qasim, and Z. A. Khan, "Simulation analysis of ieee 802.15.4 non-beacon mode at varying data rates," in Proceedings of the 7th International Conference on Broadband, Wireless Computing, Communication and Applications (BWCCA '12), pp. 46-52, IEEE, Victoria, Canada, November 2012.

[17] E. M. Shakshuki, H. Malik, and T. Sheltami, "WSN in cyber physical systems: Enhanced energy management routing approach using software agents," Future Generation Computer Systems, vol. 31, no. 1, pp. 93-104, 2014.

[18] A. Willig, M. Kubisch, C. Hoene, and A. Wolisz, "Measurements of a wireless link in an industrial environment using an IEEE 802.11-compliant physical layer," IEEE Transactions on Industrial Electronics, vol. 49, no. 6, pp. 1265-1282, 2002.

[19] L. Catarinucci, R. Colella, G. Del Fiore et al., "A cross-layer approach to minimize the energy consumption in wireless sensor networks," International Journal of Distributed Sensor Networks, vol. 2014, Article ID 268284, 11 pages, 2014.

[20] N. Zogovic, G. Dimic, and D. Bajic, "PHY-MAC cross-layer approach to energy-efficiency and packet-loss trade-off in lowpower, low-rate wireless communications," IEEE Communications Letters, vol. 17, no. 4, pp. 661-664, 2013.

[21] Y. M. Zhang, W. Q. Xu, J. Huang, Y. M. Wang, T. Shu, and L. G. Liu, "Optimal cross-layer power control and congestion control providing energy saving for ad hoc networks," Journal of Software, vol. 24, no. 4, pp. 900-914, 2013.

[22] J. Zuo, C. Dong, H. V. Nguyen, S. X. Ng, L.-L. Yang, and L. Hanzo, "Cross-layer aided energy-efficient opportunistic routing in ad hoc networks," IEEE Transactions on Communications, vol. 62, no. 2, pp. 522-535, 2014.

[23] P. Medagliani, G. Ferrari, V. Gay, and J. Leguay, "Cross-layer design and analysis of WSN-based mobile target detection systems," Ad Hoc Networks, vol. 11, no. 2, pp. 712-732, 2013.

[24] G. Lu, B. Krishnamachari, and C. S. Raghavendra, "An adaptive energy-efficient and low-latency MAC for data gathering in wireless sensor networks," in Proceedings of the 18th International Parallel and Distributed Processing Symposium (IPDPS '04), pp. 3091-3098, IEEE, April 2004.

[25] F. Cuomo, A. Abbagnale, and E. Cipollone, "Cross-layer network formation for energy-efficient IEEE 802.15.4/ZigBee Wireless Sensor Networks," Ad Hoc Networks, vol. 11, no. 2, pp. 672-686, 2013.

[26] ZigBee Alliance, ZigBee Specification, 2005, http://read.pudn .com/downloads150/doc/fileformat/648613/ZigBee-Specification-v1.0.pdf.

[27] Z. W. Jiang, X. Zhou, Y. She et al., "Research status of MAC protocols in IEEE802.15.4," Radio Communications Technology, vol. 39, no. 5, pp. 11-14, 2013.

[28] M. Valero, S. S. Jung, A. G. Bourgeois, and R. Beyah, "An incrementally deployable energy efficient 802.15.4 MAC protocol (DEEP)," Ad Hoc Networks, vol. 10, no. 7, pp. 1238-1252, 2012.

[29] C. E. Perkins and E. M. Royer, "Ad-hoc on-demand distance vector routing," in Proceedings of the 2nd IEEE Workshop on Mobile Computing Systems and Applications (WMCSA '99), pp. 90-100, IEEE, New Orleans, La, USA, February 1999.

[30] Z. Y. Sun and X. F. Xing, "Regular region algorithm optimal coverage and connectivity in WSN," Computer Science, vol. 38, no. 5, pp. 79-82, 2011.

[31] M. S. Iqbal and H. S. Al-Raweshidy, "Performance evaluation of IEEE 802.15.4 standard for low data rate ad hoc wireless sensor networks," in Proceedings of the 2nd International Conference on Control, Automation and Information Sciences (ICCAIS '13), pp. 300-304, November 2013.

[32] Z. Xing, Research of the Secure Routing Protocol for WIA-PA Network Based on DSR, Southwest University, 2013. 

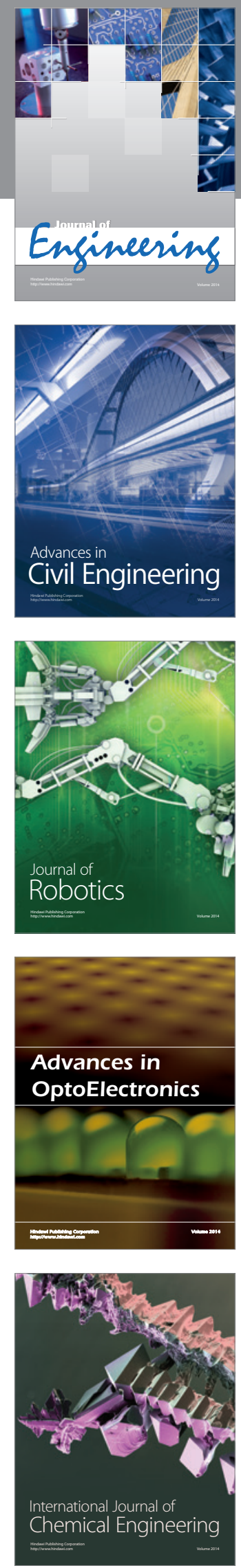

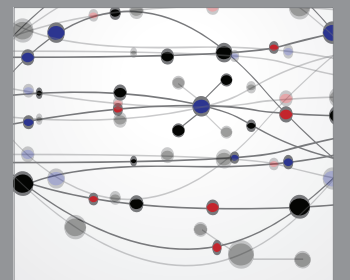

The Scientific World Journal
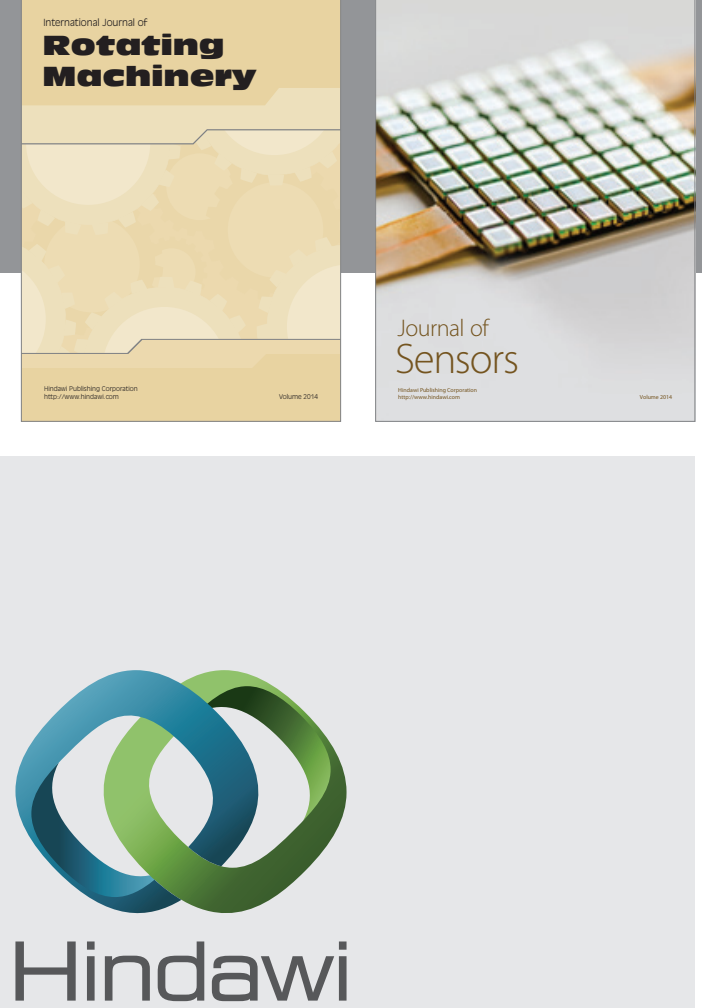

Submit your manuscripts at http://www.hindawi.com
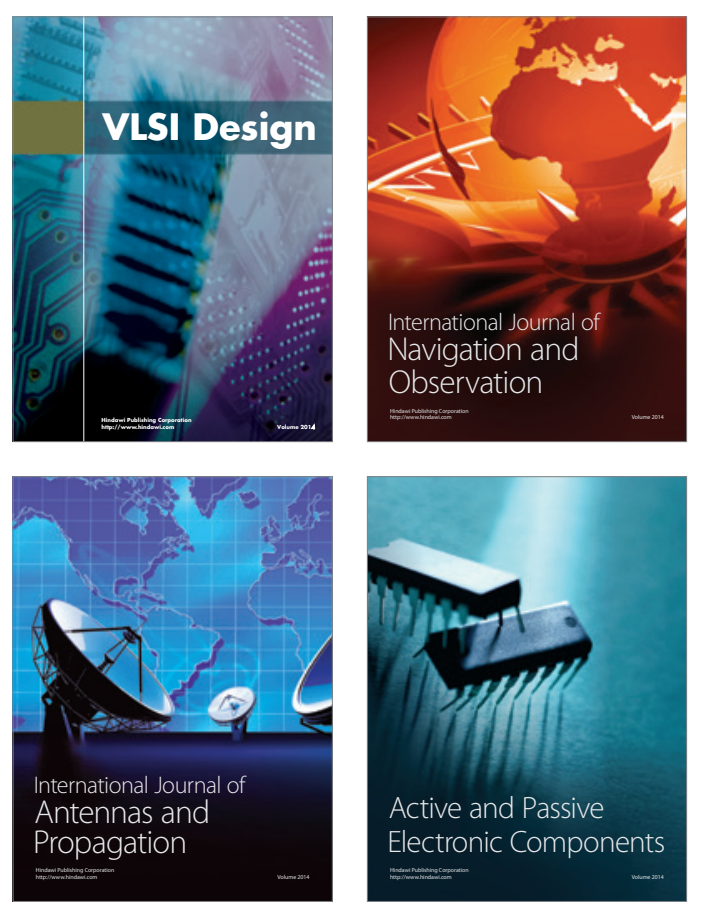
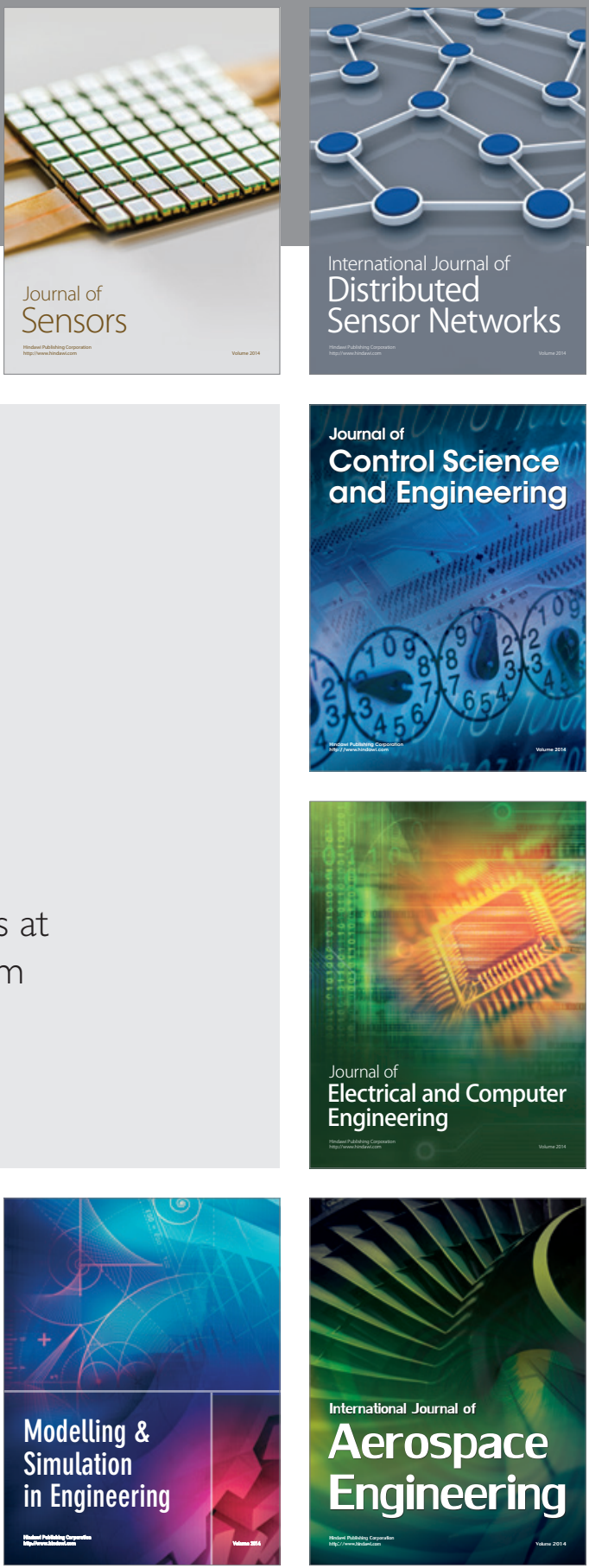

Journal of

Control Science

and Engineering
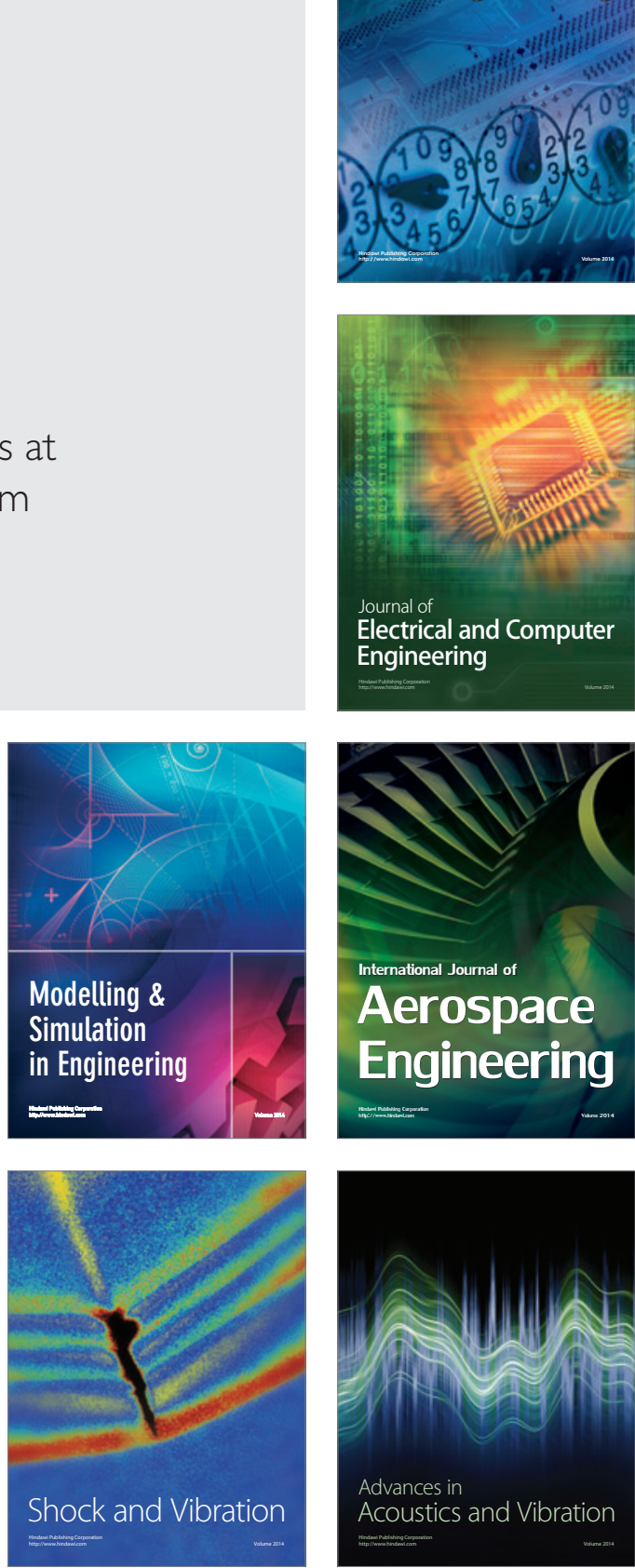